\title{
Platelet Count - To Wait or Not to Wait? That Is the Question
}

\author{
Nitin K. Sethi \\ Department of Neurology, New York-Presbyterian Hospital, Weill Cornell Medical Center, New York, N.Y., USA
}

Dear Sir,

I read with interest the recent study by Breuer et al. [1].The authors conclude that as baseline thrombocytopenia is very rare in patients presenting with acute ischemic stroke, waiting for the platelet count (PC) causes an unsubstantiated delay of thrombolysis therapy. While this may well be true, the decision to initiate or withhold intravenous thrombolysis while awaiting the PC should ideally be made on a case-tocase basis after consideration of a composite of factors such as the age of the patient, absolute PT and INR values, CT findings, history of recent hemorrhage, and history of diseases with a predisposition to thrombocytopenia. In a patient where the pretreatment CT scan demonstrates early signs of an evolving infarct, waiting for the PC may be well advised as these patients may harbor a higher risk for symptomatic intracerebral hemorrhage if the PC is less than $100,000 / \mu l$.

\section{Disclosure Statement}

Dr. Sethi serves as an Associate Editor of The Eastern Journal of Medicine.

\section{References}

1 Breuer L, Huttner HB, Kiphuth IC, Ringwald J, Hilz MJ, Schwab S, Köhrmann M: Waiting for platelet counts causes unsubstantiated delay of thrombolysis therapy. Eur Neurol 2013; 69:317-320.

\section{KARGER}

(C) 2013 S. Karger AG, Basel

0014-3022/13/0704-0185\$38.00/0
Nitin K. Sethi, MD

New York-Presbyterian Hospital

Weill Cornell Medical Center

525 East 68th Street, New York, NY 10065 (USA)

E-Mail sethinitinmd@ hotmail.com 